\title{
Una estrategia para la organización y clasificación de producciones audiovisuales UNPA
}

\author{
A strategy for the organization and classification of audiovisuales productions UNPA \\ Viviana E. Godoy, Marta Bianchi \\ vivig82@hotmail.com,martapilarbianchi@gmail.com \\ Departamento de Ciencias Sociales- Unidad Académica Caleta Olivia- Universidad Nacional \\ de la Patagonia Austral- Acceso Norte, Ruta 3 s/n - Caleta Olivia- Santa Cruz-Argentina-
}

Recibido: 01/07/2019. Aceptado: 07/10/2019

\begin{abstract}
RESUMEN
Este documento muestra el trabajo de catalogado y organización de un banco de datos que sistematiza la producción audiovisual constitutiva del patrimonio de la Unidad Académica Caleta Olivia (UACO), Universidad Nacional de la Patagonia Austral (UNPA). El trabajo se ha desplegado como alumna becaria en el marco del proyecto de investigación La producción audiovisual en la UNPA- UACO, en el periodo 2004-2016, cuyo objetivo general se vincula con describir las condiciones de producción, prácticas y dinámicas de la realización audiovisual en esa unidad académica.

Uno de los objetivos particulares, sobre el cuál se trabajó concretamente desde esta propuesta, es la creación de un archivo o banco de datos con las producciones del período de referencia, que se encontraban sin sistematizar ni organizar. Si bien el proyecto de investigación sigue su curso, la discusión generada tuvo incidencia en la forma de catalogado de las producciones y en las decisiones respecto de la manera de organizarlas para que puedan ser consultadas por usuarios en general.

Reviste especial importancia este trabajo, dado que es clave en la preservación de la memoria local, su organización y administración en tanto patrimonio.
\end{abstract}

Palabras clave: Producciones audiovisuales; Clasificación; Patrimonio; Memoria.

\begin{abstract}
This document shows the work of cataloging and organization of a data bank that systematizes audiovisual production constitutive of the patrimony of the Caleta Olivia Academic Unit (UACO), National University of Southern Patagonia (UNPA).The work has been deployed as a student intern in the framework of the research project Audiovisual Production at UNPA-UACO, in the period 20042016, whose general objective is to describe the production conditions, practices and dynamics of audiovisual production in that academic unit.

One of the particular objectives, on which we worked specifically from this proposal, is the creation of a file or database with the productions of the reference period, which were not systematized or organized. Although the research project is ongoing, the generated discussion had an impact on the way catalogs of the productions are made and on the decisions regarding how to organize them so that they can be consulted by users in general.
\end{abstract}


This work is especially important, given that it is key in the preservation of local memory, its organization and administration as a heritage.

Key words: Audiovisual productions; classification; heritage; memory.

\section{INTRODUCCIÓN}

En 1980 la UNESCO incluyó a los archivos audiovisuales como parte del Patrimonio Cultual de la Humanidad instando a preservarlos y salvaguardarlos. "Todo registro audiovisual es una nueva forma de memoria tecnológica que hace a un patrimonio cultural" (Ceranto, V., 2013).

La UNPA y específicamente la Unidad Académica Caleta Olivia, desde 2004 produce material audiovisual de diferentes características, géneros y formatos. Existen en principio casi dos centenares de piezas audiovisuales. Estas producciones nutren la propia historia universitaria y la regional. Al momento de iniciar este trabajo no estaban catalogadas ni organizadas, esta situación genera una demanda de organización para el acceso, que requiere la clasificación y organización de los productos audiovisuales para facilitar su recuperación y visionado. Numerosos autores reconocen la importancia de los archivos audiovisuales, su organización y disposición para contribuir de manera efectiva a la memoria colectiva. (Edmondson, Audiovisual Archiving Philosophy Interest Network, \& Unesco, 2008)L; (Repetto Málaga, L., 2006)

La UNPA se ha adaptado para la creación de sus audiovisuales al permanente cambio de las políticas y los condicionamientos económicos desde el año 2004. En este contexto el Área de Comunicación Institucional ha sido generadora, junto a otros actores universitarios, de productos audiovisuales para el desarrollo de las actividades académicas y promoción de proyectos de extensión vinculados a la educación y a las actividades con la comunidad.

Desde la aprobación de la Ley de Servicios de Comunicación Audiovisual 26.522 en el año 2009, surgen nuevos escenarios comunicacionales a nivel nacional y la UNPA asume un papel protagónico para el desarrollo de producciones audiovisuales en la provincia de Santa Cruz. La creación de los polos audiovisuales facilita la realización de piezas con identidad regional, reflejando problemáticas sociales y reforzando los vínculos con la comunidad. La incorporación de las nuevas tecnologías permite la visualización de estas producciones a través de la web, por lo tanto para la UNPA es importante la consolidación de un archivo audiovisual, que concentre y organice cronológicamente los hitos de su patrimonio audiovisual y que permita sumar las producciones futuras en su estructura.

En este sentido aspiramos a contribuir a la construcción de la memoria colectiva e institucional, considerando que "la memoria en el mundo contemporáneo es una memoria sobre todo archivista que descansa enteramente en la materialidad de la huella, en la inmediatez del registro, en la visibilidad de la imagen" (Nora \& Kritzman, 1996)

Finalmente cabe destacar que el presente proyecto se inscribe en la línea de preservación de la memoria, historia y cultura de la institución y la localidad. Es el primer proyecto de investigación de este grupo. Dialoga directamente con otras áreas de Comunicación 
Audiovisual y Social de Universidades Argentinas, tales como la Facultad de Ciencias de la Comunicación de la Universidad Nacional de Córdoba o la Carrera de Comunicación Social de las Universidades Nacionales de Quilmes y La Plata, que trabajan en analizar y organizar archivos audiovisuales de sus producciones.

\section{MARCO DE REFERENCIA}

Cada pieza audiovisual de la UNPA- UACO se articula con aspectos económicos y políticos que marcan una época y condicionan contextualmente las producciones audiovisuales caracterizándolas, desde leyes y disposiciones que enmarcan el trabajo de producción, hasta equipamiento, estímulos, capacitación profesional y fondos que contribuyen a la realización de las mismas.

La dimensión institucional es necesaria para comprender la tipología de producciones existentes. El centro de producción fue tomando diferentes formas y nutriéndose de personal especializado y equipamiento. En la Unidad Académica Caleta Olivia (UACO), a partir del año 2004 se reabre el área de prensa (que había sufrido recortes debido a la crisis económica del año 2001) y en paralelo el desarrollo del área de generación de materiales del Programa de Educación a Distancia. Esta primer época, donde se incorporan profesionales de la comunicación al área, los productos se direccionan a la difusión de las actividades políticoacadémicas, el soporte a la bimodalidad y comunicación de la ciencia.

En el año 2007, a partir de la reforma de la estructura orgánica de la Universidad, se crean el Área de Prensa y Difusión y el Laboratorio de Medios Audiovisuales, hecho que propicia una especialización de los integrantes de estos equipos de trabajo. La producción se diferencia claramente, la primera estructura se orienta a la comunicación institucional y la segunda a la producción de contenidos de comunicación de la ciencia y de ficción.

En el año 2009 se aprueba la Ley de Servicios de Comunicación Audiovisual $\mathrm{N}^{\circ}$ 26.522, en reemplazo de la Ley de Radiodifusión $\mathrm{N}^{\circ}$ 22.285. La UNPA se constituye en cabecera del Programa Polos Audiovisuales, impulsado a la luz de la nueva ley, y crea nodos de producción audiovisual. En la UACO se constituye el Nodo Tewsen, que abarca la zona norte de Santa Cruz y sur de Chubut.

Desde el año 2010 también, se aplica el Programa de Apoyo para el Desarrollo de la Infraestructura Universitaria. El trabajo del área incluye una articulación entre el Programa de Voluntariado Universitario y los cibereducativos, promoviendo la producción de contenidos periodísticos y la autonomía en dicha producción por parte de los diferentes actores territoriales involucrados, creando una red de productores de contenidos vinculada con la UNPA y el Polo Audiovisual Patagonia Sur. "Este Polo colabora con la capacitación del personal de los cibereducativos; los dinamizadores. La idea de la capacitación es dar una formación básica que les permitirá saber cómo difundir, con un mínimo de calidad periodística, las actividades donde el cibereducativo está involucrado: actividades educativas, culturales, de inclusión digital, etc.” (Leno, L 2018)

Esta breve historia demuestra la diversidad de material audiovisual producido, influido por los cambios institucionales vinculados al área, por lo que su organización y catalogado afrontó 
algunas discusiones y toma de decisiones. Partiendo de la existencia de trabajos previos centrados en analizar y organizar producciones audiovisuales tales como los de la Facultad de Artes de la Universidad Nacional de Córdoba en la conformación del Centro de Conservación y Documentación Audiovisual (CDA) (Ceranto, V., 2013) o la Carrera de Comunicación Social de las Universidad Nacional de La Plata (Mazal, O. \& Repetto, C., 2013), se discutieron los criterios para el catalogado de las casi 200 piezas que componen el material de la UNPA UACO desde 2004.

Varios niveles se involucraron en la categorización. El género fue uno de ellos:

“...desde el punto de vista de los contenidos audiovisuales, el concepto de género es útil para orientarnos en la abundante producción mediática porque permite acometer con ciertas garantías la descripción y clasificación general de los mismos. El término género viene a designar cualquier categoría distintiva que presente identidad y formato propio. La identidad se refiere al propósito: información, programas de entretenimiento u otras variantes secundarias, mientras el formato hace alusión a la extensión, ritmo, estructura y lenguaje. Los géneros en Internet constituyen, como en cualquier otro medio de comunicación un mecanismo de clasificación de las relaciones entre el receptor y el contenido, que cumple un conjunto específico de fórmulas. (Lloret, N \& Canet, F., 2008)

Existen múltiples clasificaciones de género referidas a la producción audiovisual, todas ellas permeadas por el tipo de plataforma que involucra su difusión: no es igual la clasificación referida a producciones para cine, televisión o web. Dado que nuestra producción se orientó a su difusión por televisión y web fundamentalmente, se decidió retomar inicialmente una clasificación de Lloret y Canet (2008) que fue modificada a la luz de los contenidos específicos analizados.

Esta clasificación inicial considera: largometrajes, cortometrajes en red, microrelatos, ciberseries, ciber flash, comics interactivos, trailers digitales y videoclips online. Este nivel de clasificación se conjugó con un segundo nivel: información, ficción y entretenimiento. Información incluye documentales, entrevistas, charlas (clases, ponencias, etc), debates, informativo propiamente dicho, talk y late show, docudrama. Ficción incluye series y miniseries, películas, telenovelas, animados. Entretenimiento incluye deportes, competencias, juegos.

\section{RESULTADOS}

Tomando en cuenta los criterios antes mencionados, propusimos un ordenamiento cronológico y nos encontramos con piezas fílmicas que aún no estaban digitalizas. El proceso de esa digitalización propone un tiempo real de trabajo de acuerdo al contenido establecido en el film. Este cambio marca el avance tecnológico en las producciones amoldándose a los tiempos que corren.

Esto ameritó reunirlas en mismo archivo (anexo 1) y proponer un sistema de catalogado y clasificación de los contenidos de estas producciones. Al momento se analizaron de 180 
piezas audiovisuales de las cuales un $10 \%$ se encuentran en formato Mini DVs. y Mini VHS 8 MM en proceso de digitalización.

Primer ordenamiento:

La producción organizó "series" donde los audiovisuales tienen un formato similar y temáticas específicas: Punto Nodal; Instantáneas; Vox Populi; Conferencias; Tecnópolis; Noticiero UNPA; Ficción; Ciencia. Lejos está esta clasificación de lograr un consenso en el equipo de investigación, pero es la utilizada hasta el momento, probablemente hacia el final de la investigación ésta sufra modificaciones.

En cada solapa de la base además se ordena cronológicamente cada pieza y se detallan variables tales como: número de producto; código; título; subtítulo; año de producción; género; tema; entrevistados, actores o protagonistas; soporte; tiempo de duración y observaciones.

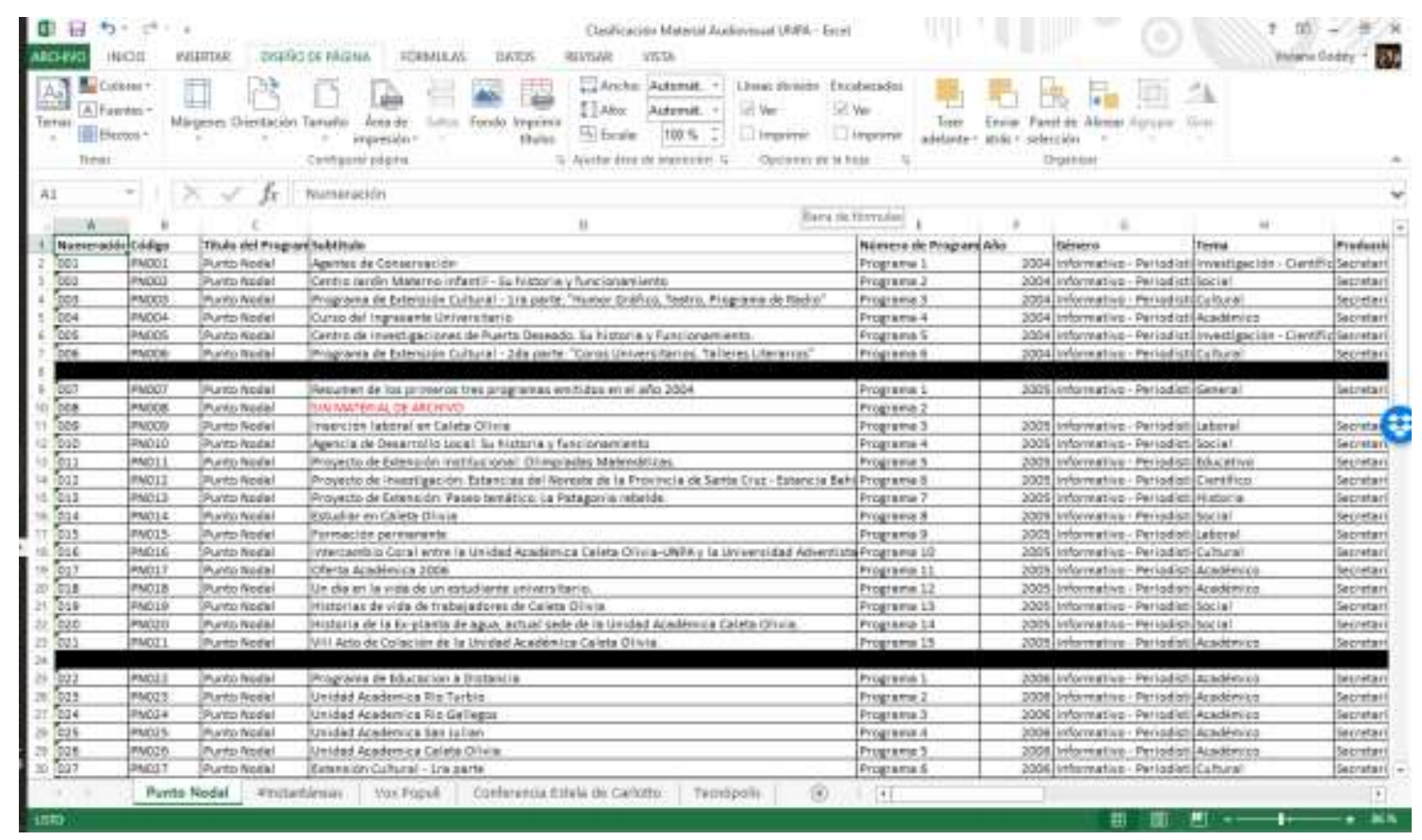

Captura de pantalla de base de datos

La mayor parte de los productos son del genero informativo, subgénero comunicación de la ciencia, documental, entrevista, y charla. Constituyen cortometrajes y micro-relatos. Los temas predominantes son: cultural-social, recreativo, artístico, institucional, político y científico. 


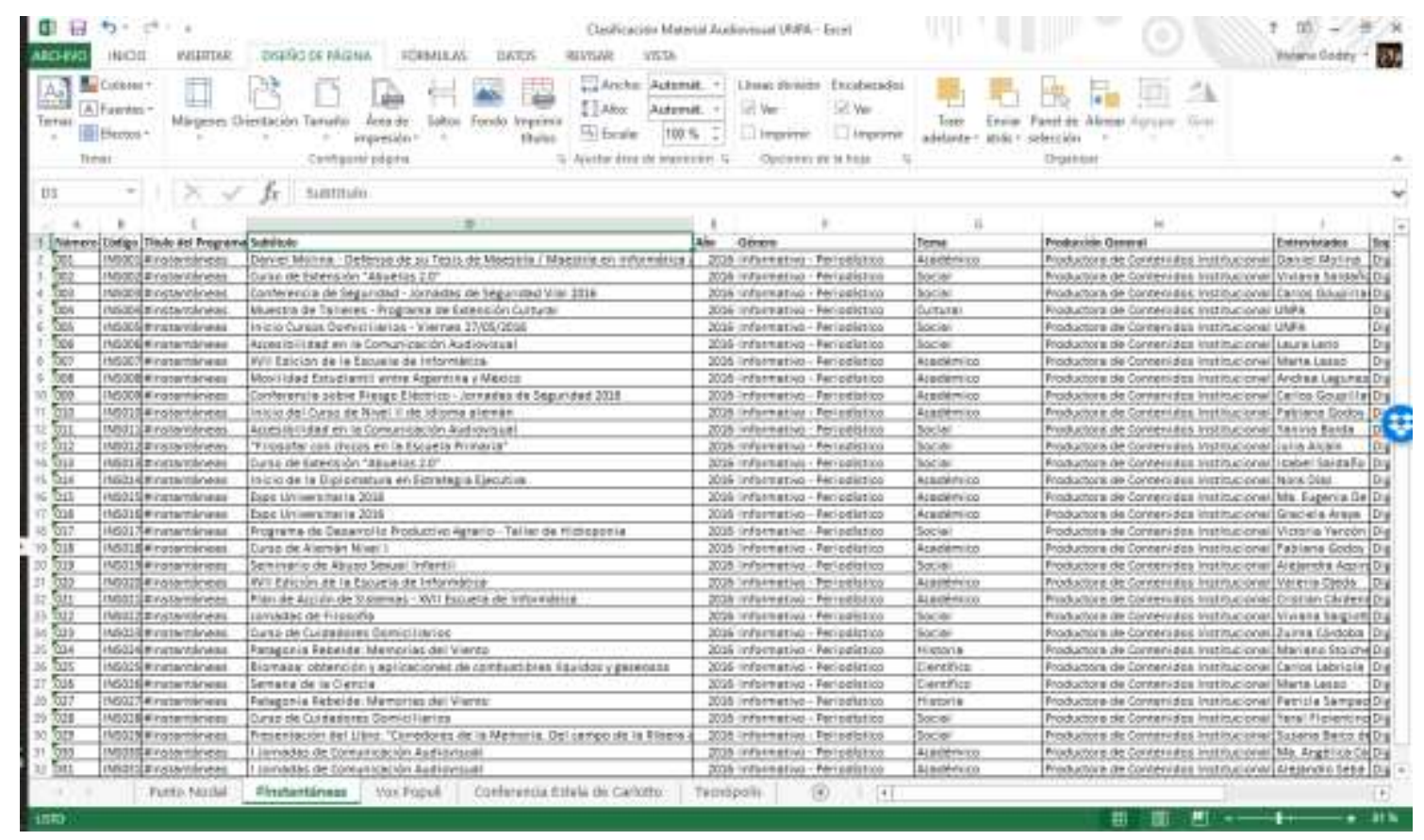

Captura de pantalla, detalle de variables

De la serie "Punto Nodal" se clasificaron 80 piezas, género informativo, que combinan temáticas institucionales-políticas con otras enfocadas en la comunicación breve de contenidos científicos.

La serie "Instantáneas" son microrelatos que difunden actividades de la Unidad Académica, tanto de Investigación como de Extensión, Deportes, Becas, Actividades de Carreras. Se catalogaron 31 piezas.

La serie "Vox Populi" muestra opiniones y conocimientos de la comunidad en torno a diversos temas de interés. Esta serie cuenta con 6 producciones.

Las series Conferencias, Tecnópolis y Noticiero UNPA enfocan en actividades especificas desplegadas en la institución, en el primer caso es un registro con escasa edición, los segundos siguen un formato informativo con objetivo de difusión institucional. Suman 40 productos audiovisuales.

Ficción y Ciencia agrupa producciones con el sello del Polo Audiovisual, Nodo Tewsen. Esta categoría queda pendiente de digitalizar.

El trabajo ha sido arduo pero provee las bases para la cuestión que aborda el becario Lucas Silva, con quien se ha trabajado de manera articulada, centrado en la disponibilidad del material para su consulta. Son aproximadamente veinte las piezas sin catalogar en esta categoría.

En paralelo al armado de la base, se digitalizó cada material y se subió a la red. En la base figura cada enlace para facilitar su reproducción. En paralelo, se organizó el archivo físico en el Área de la Productora de Medios Audiovisuales de la UNPA UACO. 


\section{CONCLUSIONES}

El resultado de este trabajo es un aporte consistente a la memoria colectiva regional en general y a la memoria institucional en particular. La importancia del patrimonio audiovisual como parte de esa memoria es un dato que exige a la institución su catalogado para ponerlo a disposición de la comunidad toda.

Hablar de patrimonio es hablar necesariamente de investigación, de inventario, de objetos materiales e inmateriales, de monumentos, de obras de arte, de documentos, de música, de tradiciones y del paisaje que los contiene. Al margen de su naturaleza, el término patrimonio encierra en su significado un sentido de bien heredado, de transmisión generacional que le confiere un valor añadido. (Salvador Benitez, A., 2017)

El patrimonio audiovisual cobra sentido pleno cuando es reconocido, valorado y apropiado por la comunidad de la cual forma parte. La convergencia tecnológica ha posibilitado que los productos audiovisuales puedan estar al alcance de un click y por tanto que su apropiación sea colectiva, a decir de Casacuberta (2003) "las obras culturales de la cultura digital ya no se construyen en forma individual, solipsista, sino de forma colectiva, organizada". Nuestro trabajo es de alguna manera el de poner a disposición este patrimonio que contribuye al desarrollo integral de nuestra sociedad, en el contexto de estos nuevos recursos tecnologicos.

Este es el objetivo final del proyecto, para lo cual el trabajo de catalogado es la piedra basal. Se ha logrado organizar el $80 \%$ de la producción audiovisual generada en la Unidad Académica Caleta Olivia entre los años 2004 y 2016. Se ha organizado a partir de ello un archivo por género/temática que posibilita el armado de una propuesta de consulta en línea. En paralelo, se han llevado adelante entrevistas con referentes institucionales que reflexionan sobre las condiciones político-económicas en las que se gestaron los productos, la estructura y equipamiento, capacitación y consolidación de grupos que permiten generar los productos audiovisuales de UNPA y de la Unidad Académica Caleta Olivia específicamente. Por otra parte, en el seno del trabajo del equipo se han sistematizado las cuestiones relativas a las variaciones del contexto legislativo y condiciones histórico-institucionales, que condicionaron la producción audiovisual. Esta reflexión, que enmarca el trabajo de catalogado y archivo, aspira a ser una contribución a las experiencias que en la región trabajan en la misma línea.

\section{AGRADECIMIENTOS}

Agradecemos muy especialmente a las Lic Castro y Serrano, que acompañaron el proceso de catalogado y sugirieron y discutieron variables para ello. Al equipo de Investigación en su conjunto, por las discusiones y aportes y al Lic. Barrionuevo por suministrar las producciones para su digitalización.

\section{REFERENCIAS}

CASACUBERTA SEVILLA, D. (2003). Creación colectiva: En Internet el creador es el público. Barcelona: Gedisa Editorial. 
CERANTO, V. (2013). El archivo audiovisual. Una aproximación a su importancia como patrimonio cultural comunitario. VI Encuentro Panamericano de Comunicación. Presentado en Cordoba. Cordoba.

EDMONDSON, R., Audiovisual Archiving Philosophy Interest Network, \& Unesco. (2008). Filosofía y principios de los archivos audiovisuales. México, D.F.: Fonoteca Nacional.

LENO, Laura. (2018). Condicionantes Historicos de la Produccion de UNPA UACO. Presentado en Jornadas Internas Comunicación Audiovisual, Caleta Olivia, UNPA UACO. https://doi.org/10.22305/ict-unpa.v8i1.156

LLORET, N, \& Canet, F. (2008). Nuevos escenarios, nuevas formas de expresión narrativa: $\mathrm{La}$ Web 2.0 y el lenguaje audiovisual. Recuperado de http://www.raco.cat/index.php/Hipertext/article/view/131950

MAZAL, O., \& Repetto, C. (2013). Preservación y producción de archivos audiovisuales. Presentado en VI Jornadas de Filología y Lingüística, La Plata, Argentina.

NORA, P., \& Kritzman, L. D. (1996). Realms of memory: The construction of the French past. volume I, volume I, . New York: Columbia University Press.

REPETTO MÁlAGA, L. (2006). Memoria y patrimonio: Algunos alcances. Recuperado de http://dialnet.unirioja.es/servlet/oaiart?codigo $=1700777$

SALVADOR BENITEZ, A. (2017). Investigación y Docencia sobre Patrimonio Audiovisual. VII Jornadas de celebración del Dia del Patrimonio Audiovisual, 6-15. Madrid: Biblioteca Nacional de España. https://doi.org/10.25145/j.pasos.2019.17.016 